\title{
Adsorption-Desorption Profile of Methylene Blue Dye on Raw and Acid Activated Kaolinite
}

\author{
Nurul Ain Safiqah Md Sandollah ${ }^{1}$, Sheikh Ahmad Izaddin Sheikh Mohd Ghazali ${ }^{1}$, \\ Wan Nazihah Wan Ibrahim ${ }^{2}$, and Ruhaida Rusmin ${ }^{1, *}$ \\ ${ }^{1}$ Faculty of Applied Sciences, Universiti Teknologi MARA, Negeri Sembilan Branch, Kuala Pilah Campus, \\ 72000 Kuala Pilah, Negeri Sembilan, Malaysia
}

${ }^{2}$ Faculty of Applied Sciences, Universiti Teknologi MARA, 40450 Shah Alam, Selangor, Malaysia

\begin{abstract}
*Corresponding author:
tel: $+606-4832100$

email: ruhaida@uitm.edu.my

Received: February 12, 2019

Accepted: August 1, 2019

DOI: $10.22146 /$ ijc. 43552

Abstract: The efficiencies of raw (RK) and acid activated (0.5 M AAK) kaolinite clay minerals to remove methylene blue $(M B)$ dyes in aqueous solution were investigated and compared. The 0.5 M AAK was prepared by treatment of RK in dilute $0.5 \mathrm{M} \mathrm{HCl} \mathrm{aqueous}$ solution under reflux. Kaolinite adsorbents were characterized and their $M B$ removal performances were evaluated via the batch method. MB desorption from spent kaolinites was investigated at $\mathrm{pH} 4$ to 8 . The MB removal was increased with increasing initial dye concentration, agitation speed and adsorbent dosage in 60 min reaction time at pH 6 . Both kaolinites showed high MB removal (up to 97\%). The Freundlich model has the bestfit equilibrium adsorption isotherm model for RK and $0.5 \mathrm{MAAK}$. The kinetic data for both adsorbents showed strong agreement with the pseudo second order kinetic model $\left(r^{2}>0.98\right)$. Nevertheless, the spent $R K$ adsorbent demonstrated a significant higher $M B$ retention than $0.5 \mathrm{MAAK}$ in desorption experiments. Kaolinite clays have great potential as cost-effective materials for dyes removal in wastewater treatment.
\end{abstract}

Keywords: kaolinite; activation; removal; dyes; desorption

\section{- INTRODUCTION}

The application of synthetic azo dyes as a commercial colorant has greatly expanded in recent years, catalyzed by the rapid growth of textile industries in the global market. In most industries, synthetic azo dyes offer advantages over natural dyes due to their simple preparation method, more diverse structure and higher stability [1]. Nevertheless, improper discharge of azo dye, such as Methylene Blue (MB) into water sources could pose negative health and environmental impacts because of their toxicity and persistency against degradation agents [2]. Therefore, it is of great importance to ensure the necessary effluent treatment was performed to avoid the deterioration of water quality. Methylene Blue (chemical formula of $\mathrm{C}_{16} \mathrm{H}_{18} \mathrm{CIN}_{3} \mathrm{~S}$ ) is a polar hydrophobic azo dye belongs to the phenothiazine family, which are commonly used in garment manufacturing, health, and chemical industries. Previously, various types of adsorbents such as activated carbon, fly ash, red mud, etc. for removing $\mathrm{MB}$ from aqueous solution have been reported [3]. Although the activated carbon is so far being considered as the most common adsorbent for dyes removal, its expensive preparation cost and regeneration issues have limited their application and are economically unfavorable [4].

Clay minerals are colloid particles built from the interaction of rocks, soils, and sediments. Clay minerals are known as hydrated aluminium silicates that consist of a layered structure made up of tetrahedral sheets that link to an octahedral sheet by sharing of apical oxygen [5]. The detailed structure of clay minerals has been widely discussed elsewhere [6-7]. Naturally, clay minerals have the ability to remove toxic compounds from the environment and reducing the dispersion of pollutants in soil and water $[5,8]$. These materials are considered as suitable alternative materials over expensive commercial activated carbon due to their 
abundance, low cost, environmentally friendly, multiple ion exchange properties and less toxicity [8].

Kaolinite is categorized as a 1:1 ( 1 tetrahedral sheet and 1 octahedral sheet) class of clay minerals with nonswelling properties [5] and chemical composition of $\mathrm{Al}_{2} \mathrm{Si}_{2} \mathrm{O}_{5}(\mathrm{OH})_{4}$. In Malaysia, kaolinite resources exist mainly in the states of Johor, Perak, and Pahang, with the estimated annual production of over 500,000 tons in 2013 [9]. Even though kaolinite clays are abundant in Malaysia, this natural resource is still limitedly used in wastewater treatment studies. Thus, the performance of kaolinite clays in removing dyes remains underexplored and warrants detail assessment.

Surface modification of raw kaolinite is usually necessary as this clay is less reactive and has a smaller specific surface area as compared to other clay minerals (e.g. bentonite) [10]. So far, the acid activation technique has been the most useful, cheap, simple and common method for modifying the kaolinite to achieve desirable attributes [11]. Acid activation is defined as the treatment of clay minerals with inorganic acids at a particular temperature in order to increase the acidity, surface area, and porosity of the clays [11]. Although concentrated acid was reported to produce better results in terms of high surface area and porosity [12], the highly acidic leachant is potentially hazardous, less ergonomic and could pose an environmental concern if untreated. Low concentration of acid (less than $2 \mathrm{M}$ ) was recommended to ensure no significant alteration of clay's basic structure [13]. Furthermore, it is recently reported that low acid concentration is already sufficient for higher adsorption towards pollutant, as demonstrated by the activated kaolinite prepared from dilute acid $\left(0.5 \mathrm{M} \mathrm{H}_{2} \mathrm{SO}_{4}\right)$ used to remove Crystal Violet and Brilliant Green dyes [14]. In another research, a $0.5 \mathrm{M} \mathrm{HNO}_{3}$ acid was used to activate Moroccan Clay that yields a high adsorption capacity (500 mg/g) towards Methylene Blue [15]. To the best of our knowledge, acid activation of kaolinite using dilute hydrochloric acid has not been thoroughly discussed in the literature. Hence, this study aims to use dilute inorganic acid in treating kaolinite and evaluate its performance against raw kaolinite in removing Methylene Blue $(\mathrm{MB})$ in aqueous solution. The MB adsorption is investigated under various experimental parameters (e.g. pH, adsorbent loading, time and initial concentration) to assess their adsorption characteristics and deduce the reaction mechanism. This study also aims to give an insight into the suitability of spent kaolinite to be recycled for water treatment application as an approach to support environment sustainability. For this purpose, the MB retention stability in spent kaolinites is studied through the desorption experiment to assess its regeneration capabilities. The findings of this study will provide an insight into the potential of kaolinites as a cost-effective and efficient adsorbent for water remediation technologies.

\section{- EXPERIMENTAL SECTION}

\section{Materials}

Kaolinite clay mineral (purchased from MyLab Supplier, Malaysia) was used without further purification. Methylene blue (C.I. 52015, from Merck) was purchased from R\&M Chemicals. Hydrochloric acid $(\mathrm{HCl}, 37 \%)$ and sodium hydroxide $(\mathrm{NaOH}, 96 \%)$ were supplied by R\&M Chemicals and of analytical grade.

\section{Instrumentation}

$\mathrm{X}$-ray powder diffraction (XRD) pattern in the $2 \theta$ range $10^{\circ}$ to $90^{\circ}$ was recorded with Panalytical model Empyrean (Panalytical, Almelo, Netherlands) operating at $40 \mathrm{kV}$ and $35 \mathrm{~mA}$ using $\mathrm{Cu} \mathrm{Ka}$ radiation $(\lambda=1.54059 \AA)$. The Fourier transformed infrared spectroscopy (FTIR) spectra were recorded on Perkin-Elmer infrared spectrophotometer using ATR mode with a resolution of $4 \mathrm{~cm}^{-1}$ in the range of $4000-650 \mathrm{~cm}^{-1}$. Zeta potential analysis was performed using a Zetasizer 1600 Zeta Potential and Size Analyzer (Malvern Instrument). A $0.05 \%(\mathrm{~m} / \mathrm{v})$ kaolinite suspension (prepared at $\mathrm{pH} 4,6$ and 8) was prepared and analyzed in duplicates at $25^{\circ} \mathrm{C}$.

\section{Procedure}

\section{Acid activation of kaolinite}

Acid activation of raw kaolinite was performed according to a previous report [16]. A $20.0 \mathrm{~g}$ of raw kaolinite (RK) was refluxed at $70{ }^{\circ} \mathrm{C}$ with $0.5 \mathrm{M} \mathrm{HCl}$ for $3 \mathrm{~h}$. The resulting materials were centrifuged and washed with water several times until all $\mathrm{Cl}^{-}$was 
removed as confirmed by the $\mathrm{AgNO}_{3}$ test. Then, the products were oven-dried at $60^{\circ} \mathrm{C}$ until a constant weight was obtained. The acid activated kaolinite was labelled as $0.5 \mathrm{M} \mathrm{AAK}$ (kaolinite treated with $0.50 \mathrm{M} \mathrm{HCl}$ ).

\section{Adsorption experiment}

Methylene Blue (MB) stock solution (100 ppm) was first prepared by dissolving accurate weight of $\mathrm{MB}$ in deionized water and then diluted to pre-determined concentration (20,30, 40, 50 and $70 \mathrm{ppm})$. MB adsorption experiments on raw and activated kaolinites were carried out through a batch method at $25^{\circ} \mathrm{C}$ in a $15 \mathrm{~mL}$ centrifuge tube at various experimental parameters. Experiments were performed at $\mathrm{pH} 4,6$, and 8 (adjusted using $0.01 \mathrm{M}$ $\mathrm{NaOH}$ or $\mathrm{HCl}$ ) to evaluate the influence of $\mathrm{pH}$. The contact time was varied from 10 to $180 \mathrm{~min}$ until equilibrium was reached. The effect of initial concentration was studied in concentration range up to $70 \mathrm{ppm}(\mathrm{mg} / \mathrm{L})$. Meanwhile, the effect of adsorbent loading was investigated using a $0.01,0.03$ and $0.05 \mathrm{~g} / \mathrm{mL}$ loading. The kinetic study was performed at the optimized condition at the initial concentration of $50 \mathrm{ppm}$. The removal percentage at different agitation speed (1000, 1500 , and $2500 \mathrm{rpm}$ ) was also tested. The aliquots were centrifuged at $2500 \mathrm{rpm}$ and the concentration of MB in the supernatant before and after adsorption were determined using UV-Vis spectrophotometer [T80+, PG instrument Ltd] at wavenumber $668 \mathrm{~nm}$.
The removal percentage of MB by kaolinite was calculated using Eq. (1):

Removal percentage $(\%)=\frac{[\mathrm{MB}]_{\text {initial }}-[\mathrm{MB}]_{\text {final }}}{[\mathrm{MB}]_{\text {initial }}} \times 100 \%$

\section{Desorption experiment}

Desorption experiment was performed using spent kaolinites (RK and 0.5 M AAK) previously used in treating a $50 \mathrm{mg} / \mathrm{L} \mathrm{MB}$ aqueous solution (performed at the optimized condition of $\mathrm{pH}=6$, loading $=0.05 \mathrm{~g} / \mathrm{mL}$, and agitation speed $=2500 \mathrm{rpm}$ ). The spent kaolinites were placed in deionized water at $\mathrm{pH} 4,6$ and 8 (adjusted using $0.1 \mathrm{M} \mathrm{HCl}$ or $0.1 \mathrm{M} \mathrm{NaOH}$ ) under agitation. Desorption process was performed in $60 \mathrm{~min}$ and the supernatant was collected through centrifugation. The concentration of desorbing MB was determined using the UV-Vis spectrometer. The MB desorption percentage was calculated according to Eq. (2):

Percent desorption $(\%)=\frac{[\mathrm{MB}]_{\text {desorbed }}}{[\mathrm{MB}]_{\text {adsorbed }}} \times 100 \%$

\section{- RESULTS AND DISCUSSION}

\section{Characterization}

The XRD patterns of raw and activated kaolinites are shown in Fig. 1. The important characteristic peaks of kaolinite were located at $2 \theta$ of 12.6 and $24.9^{\circ}$ associated with [001] reflection [17]. Other peaks at 34.8, 35.9 , and $38.5^{\circ}$ were also associated with kaolinite. These
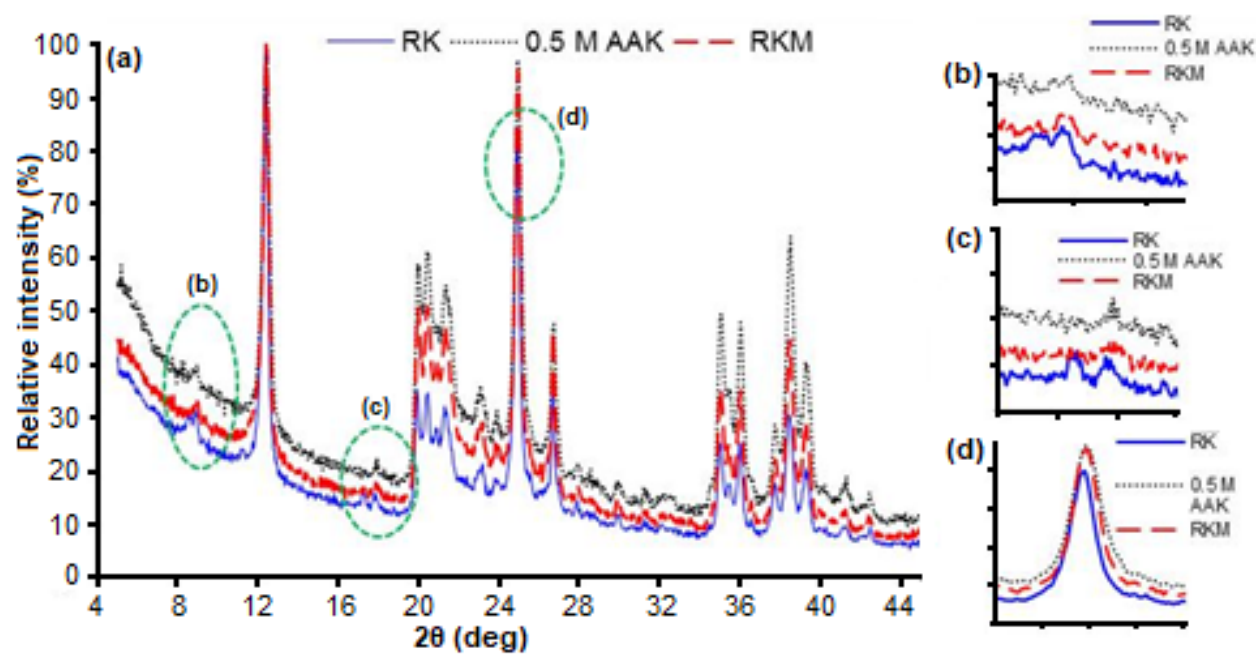

Fig 1. XRD diffractogram of raw (RK), $0.5 \mathrm{M} A A K$ and raw kaolinite loaded with $\mathrm{MB}$ (RKM) 
sharp and intense peaks indicate kaolinite as the dominant minerals present with a high degree of crystallinity. A trace of illite $\left(2 \theta=8.5\right.$ and $\left.17.1^{\circ}\right)$ (Fig. 1 (bc)) as impurities was noticed [10]. The illite peak was almost diminished in 0.5 M AAK diffractogram denoting dissolvation of this mineral due to acid attack. Neither alteration in the diffraction pattern nor peak shifting was observed in the acid activated kaolinite (0.5 M AAK) (Fig. 1(d)). To elucidate the possible interaction of MBkaolinite, the XRD pattern of the spent raw kaolinite loaded with MB (assigned as RKM) was acquired (Fig. 1). No significant variation (i.e. peak shifting or broadening) with respect to the RK diffractogram was observed. This shows that the MB interacts only on the surface of the kaolinite without any intercalation on the clay's interlayer.

The FTIR spectra of raw and activated kaolinites are shown in Fig. 2(a). Kaolinite has typically four distinct absorption bands of the hydroxyl group in the range of $3700-3620 \mathrm{~cm}^{-1}$ [18-19]. The interlayer hydroxyl stretching mode of Al-OH was located at 3653 and $3667 \mathrm{~cm}^{-1}$ (outof-plane vibration) as well as at $3697 \mathrm{~cm}^{-1}$ (symmetric stretching). The band at $3620 \mathrm{~cm}^{-1}$ is representing the stretching vibration of the internal hydroxyl group of Al$\mathrm{OH}$ lying between the tetrahedral and octahedral sheets [20]. The Si-O-Si/Al asymmetric and symmetric stretching could be observed at 1033 and $790 \mathrm{~cm}^{-1}$, respectively [7]. The bands at 913 and $938 \mathrm{~cm}^{-1}$ were attributed to the $\mathrm{OH}$ deformation modes of inner andsurface hydroxyls groups, respectively [7]. Whereas the band located at $755 \mathrm{~cm}^{-1}$ was ascribed to the $\mathrm{Si}-\mathrm{O}$ vibration of the clay sheet [7]. All these bands confirmed the presence of kaolinite, which is in agreement with the
XRD patterns described earlier. The differences in IR spectra of activated kaolinites were closely examined in the $\mathrm{OH}$ stretching region ( 3700 to $3650 \mathrm{~cm}^{-1}$ ) (Fig. 2(a), inset). A slight broadening of the Al-OH stretching band at $3697 \mathrm{~cm}^{-1}$ was observed in the $0.5 \mathrm{M} \mathrm{AAK}$ (Fig. 2(a), inset). This observation suggested a minor perturbation occurred in the kaolinite octahedral sheets caused by cation leaching during acid activation [14].

Meanwhile, the zeta potential analysis (Fig. 2(b)) showed that both RK and $0.5 \mathrm{M}$ AAK had a negative surface charge at $\mathrm{pH}$ range 4 to 8 , as usually observed for clay mineral materials [8]. This negative surface change was contributed by the protonation/deprotonation of the surface hydroxyl group (aluminol or silanol) of the broken edge of kaolinite's plane. At pH 6, the $0.5 \mathrm{M} \mathrm{AAK}$ showed a much more negative surface charge compared to RK; which could lead to a higher electrostatic interaction with the cationic MB.

\section{Adsorption Experiment}

\section{Effect of initial $\mathrm{pH}$ solution on the adsorption of $M B$}

During the adsorption process, the $\mathrm{pH}$ of aqueous solution plays an important role [21], as $\mathrm{pH}$ variation could; i) alter the metals ion speciation, ii) raise ionic competition due to excess of a proton $\left(\mathrm{H}^{+}\right)$or hydroxyl ion $\left(\mathrm{OH}^{-}\right)$, and iii) affect surface properties of the adsorbate. Furthermore, clay mineral like kaolinite has two types of surfaces called basal surfaces (i.e. interlayer surfaces) and a more complex edge surfaces (i.e. broken surfaces) [17]. The basal surfaces are $\mathrm{pH}$-independent whereas edge surface sites (consist of dangling bonds like $\mathrm{Al}-\mathrm{O}, \mathrm{Si}-\mathrm{O}$ and $\mathrm{Mg}-\mathrm{O}$ ) are usually $\mathrm{pH}$ dependent (amphoteric). Thus, any changes of $\mathrm{pH}$ will result in the

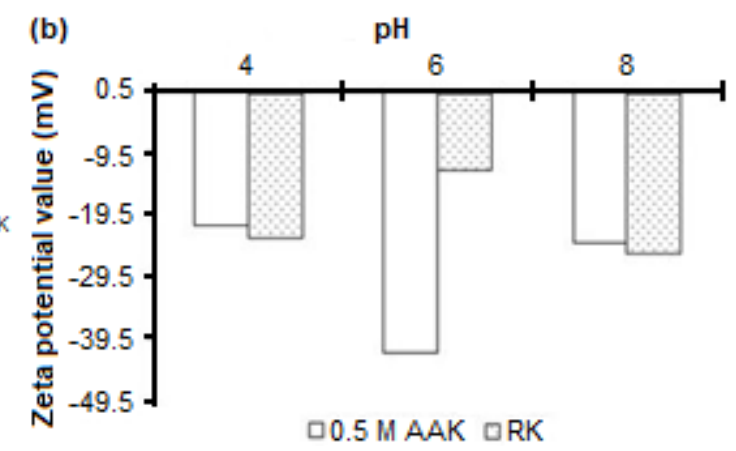

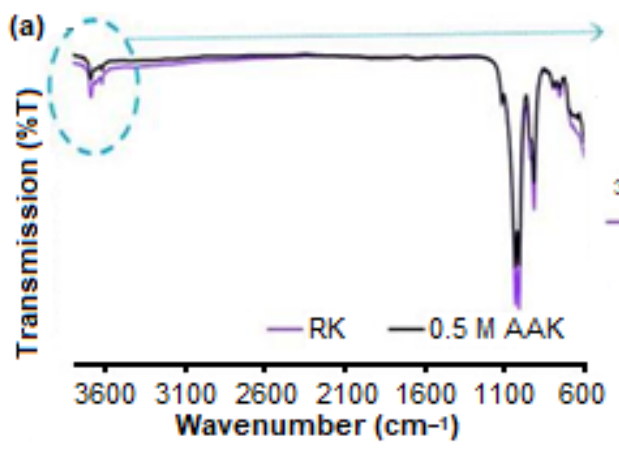

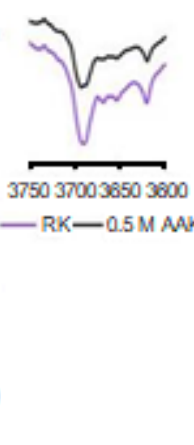

Fig 2. FTIR spectra (a) and zeta potential value (b) of raw and activated kaolinite 
protonation/de-protonation of active surface functional groups leading to a different complexing capability towards organic substances [5].

The $\mathrm{MB}$ removal by all adsorbents was lowest at $\mathrm{pH}$ 4, whereas experiments performed at $\mathrm{pH} 6$ recorded the highest percentage (Fig. 3(a)). Based on the zeta potential measurement, it was deduced that the cationic MB could potentially interact with the negative charge of the kaolinite through the electrostatic interaction [10]. Hence, in acidic suspension ( $\mathrm{pH}$ 4), the excess $\mathrm{H}^{+}$may compete with cationic $\mathrm{MB}$ for the active sites of kaolinite [10]. The acidic $\mathrm{pH}$ also induces the protonation of the surface functional groups of the kalolinite which in turn reduce the clay's attraction towards cationic MB due to repulsive electrostatic forces.

During acid activation, the $\mathrm{H}^{+}$ions (from acids in the activation process) might preferably be adsorbed on the negative surface of the clay hence altering the surface charge [5]. Yet, in this study, the removal percentage of 0.5 M AAK (96.8\%) was quite similar to the performance of the RK (95.3\%), contradicting with trends observed in previous research findings [22] and a more recent
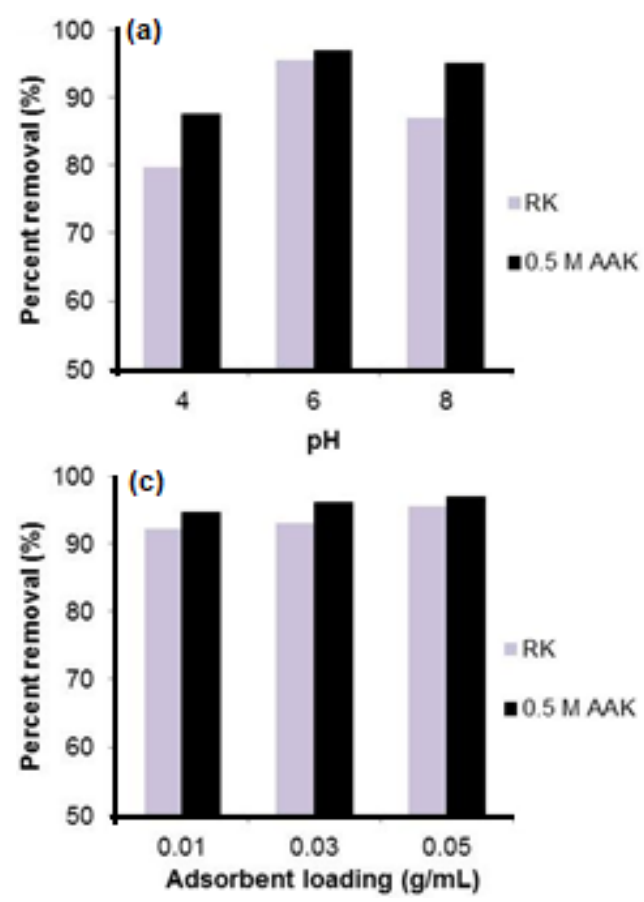

publication [23]. Meanwhile, at high $\mathrm{pH}(\mathrm{pH}$ ), less competition by $\mathrm{H}^{+}$resulted in more removal of $\mathrm{MB}$ (Fig. 3(a)). As deprotonation of $\mathrm{MB}$ in alkaline aqueous solution is considered not possible [24], the slight decrease in $\mathrm{MB}$ removal at alkaline $\mathrm{pH}$ hence is likely attributed by the changes in surface chemistry of the clays. Similar finding on the reduction of removal efficiencies of MB by kaolinite at the working condition of $\mathrm{pH}>7$ was also reported by previous researchers [25]. Thus $\mathrm{pH} 6$ was chosen as the optimum $\mathrm{pH}$ for the subsequent experiment as this $\mathrm{pH}$ provides the highest removal efficiency. We deduced that the slightly higher removal percentage of $0.5 \mathrm{MAAK}$ was governed by the removal of impurities (e.g. illite) [14] that allowed more exposed active sites, in accordance with the XRD diffractogram discussed previously. Furthermore, the 0.5 M AAK demonstrated more negative zeta potential value at this $\mathrm{pH}$ (Fig. 2(b)), thus allowing stronger interaction with $\mathrm{MB}$ as compared to the RK.

\section{Effect of time on the adsorption of $M B$}

Results demonstrated that the MB removal was gradually increased at reaction time increment (Fig. 3(b)).
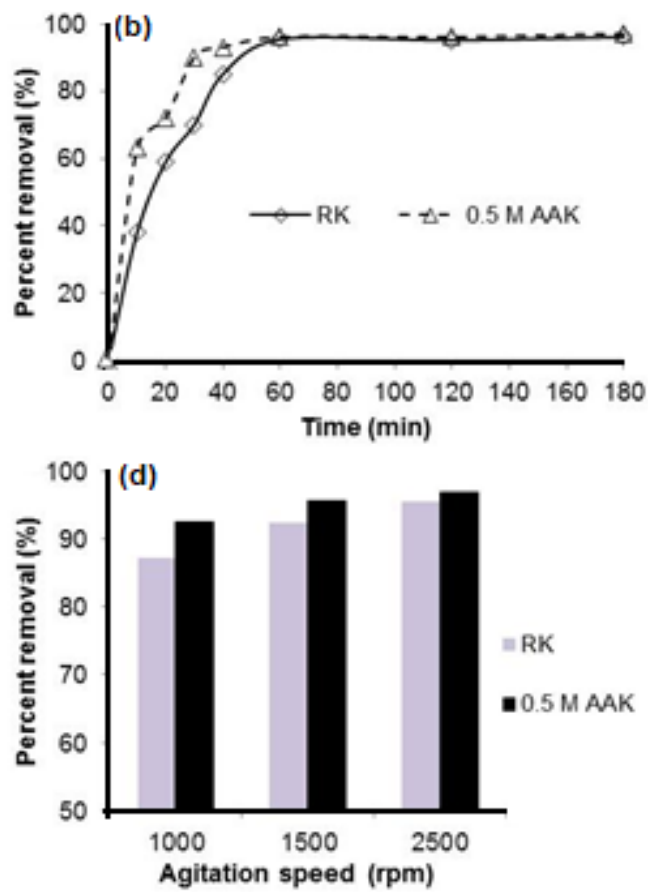

Fig 3. Effect of (a) pH; (b) time; (c) loading; and (d) agitation speed, on \% removal of $\mathrm{MB}$ (performed at temperature $=25^{\circ} \mathrm{C}$, agitation speed $=2500 \mathrm{rpm}$, adsorbent loading $=0.05 \mathrm{~g} / \mathrm{mL}$, initial concentration $=50 \mathrm{mg} / \mathrm{L}$, where appropriate) 

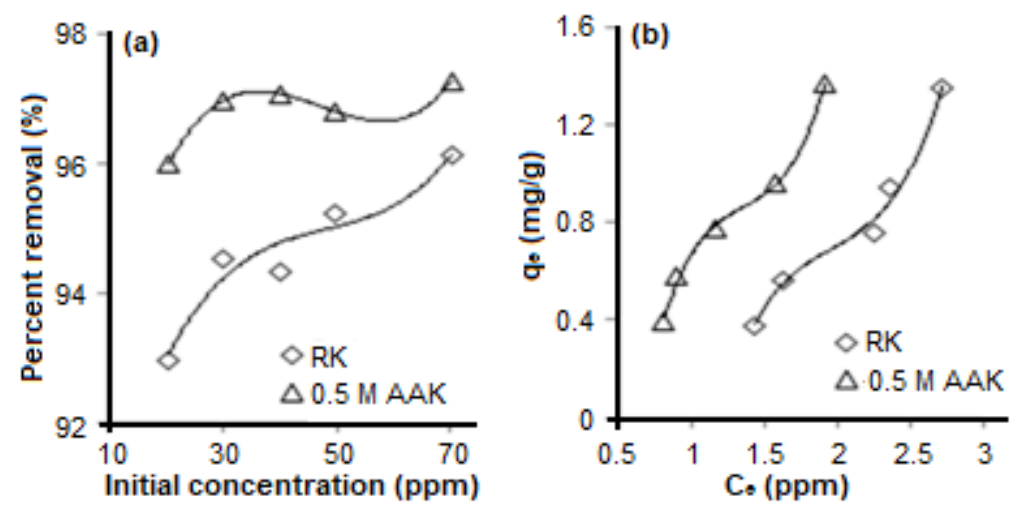

Fig 4. Effect of initial concentration towards MB removal (a), adsorption isotherm for RK and $0.5 \mathrm{M} A \mathrm{AK}$ (b)

The removal rate of RK and $0.5 \mathrm{M}$ AAK was considered fast, as more than $60 \%$ dye was successfully removed at the earliest of $20 \mathrm{~min}$ initial time (Fig. 3(b)). Overall, the equilibrium was attained after $60 \mathrm{~min}$ and the $\mathrm{MB}$ removal remained constant henceforth. The fast $\mathrm{MB}$ uptake by all kaolinites indicated a strong interaction between $\mathrm{MB}$ and active sites on the kaolinite surface [4].

\section{Effect of adsorbent loading on the adsorption of MB}

For all adsorbents, the removal of $\mathrm{MB}$ was enhanced as the adsorbent dosage was increased (Fig. 3(c)). These findings were ascribed to more availability of surface active sites of the adsorbent. The sufficient active sites will allow more MB to be deposited and adsorbed [25]. The removal percentage of $\mathrm{RK}$ and $0.5 \mathrm{M}$ AAK was maintained at above $>90 \%$ for all adsorbent loading. This implies that both adsorbents have abundance active sites with high affinity towards MB.

\section{Effect of agitation speed on the adsorption of MB}

Agitation is one of the important parameters in adsorption phenomena as it influences the distribution of the solute in the bulk solution and reduces the mass transfer effect. The MB removal efficiency was enhanced with the increase in agitation speed (Fig. 3(d)). At 2500 rpm, up to $96 \%$ of MB was successfully removed (Fig. 3(d)). High agitation speed may provide more energy to minimize the mass transfer phenomenon [26] and promote the more interfacial area of contact between adsorbent (clay)-adsorbate (MB). Hence, a higher removal percentage in an allocated time can be achieved.

\section{Effect of initial concentration on the adsorption of MB}

A high initial dye concentration provides a sufficient driving force to overcome the mass transfer resistance between the aqueous and solid phases [27]. It was observed that at an initial concentration of $20 \mathrm{ppm}$, more than $90 \% \mathrm{MB}$ removal was recorded by all adsorbents (Fig. 4(a)). The maximum adsorption capacity attained for RK and $0.5 \mathrm{M} \mathrm{AAK}$ at an initial concentration of 20 to $70 \mathrm{ppm}$ was 1.35 and $1.37 \mathrm{mg} / \mathrm{g}$, respectively (Fig. 4(b)).

\section{Adsorption isotherm}

To determine the best-fit adsorption isotherm model in describing the MB adsorption, the adsorption data were fitted into four models; namely Langmuir, Freundlich, Dubinin-Radushkevich (D-R) and Temkin model (Table 1). The Langmuir isotherm model works based on the assumption of a monolayer and uniform energies of adsorption. The Langmuir constant $\left(\mathrm{K}_{\mathrm{L}}\right)$ and the maximum adsorption capacity $\left(\mathrm{q}_{\max }\right)$ were respectively obtained from the slope and the intercept of a linearised Langmuir equation, shown by Eq. (3):

$\frac{\mathrm{C}_{\mathrm{e}}}{\mathrm{q}_{\mathrm{e}}}=\frac{1}{\left(\mathrm{q}_{\max } \mathrm{K}_{\mathrm{L}}\right)}+\frac{\mathrm{C}_{\mathrm{e}}}{\mathrm{q}_{\max }}$

where $\mathrm{q}_{\mathrm{e}}$ and $\mathrm{C}_{\mathrm{e}}$ is the adsorbed amount of $\mathrm{MB}(\mathrm{mg} / \mathrm{g})$ and concentration of $\mathrm{MB}(\mathrm{mg} / \mathrm{L})$ at equilibrium, respectively [10].

Meanwhile, the Freundlich isotherm model assumes a heterogeneous surface site with multilayer 
adsorption, and could be expressed by the following relationship (Eq. (4)):

$\log _{\mathrm{qe}}=\log _{\mathrm{Kf}}+\frac{1}{\mathrm{n}} \log \mathrm{C}_{\mathrm{e}}$

$\mathrm{K}_{\mathrm{f}}$ is the Freundlich constant $(\mathrm{L} / \mathrm{g})$, meanwhile, the $1 / \mathrm{n}$ denotes the adsorption intensity [28].

Temkin model [29] takes into account the adsorbing species-adsorbent interactions at the solid/liquid interface equilibrium. The intercept and slope of $\mathrm{q}_{\mathrm{e}}$ plotted versus $\ln C_{e}$ in the following Temkin equation (Eq. (5)):

$\mathrm{q}_{\mathrm{e}}=\mathrm{B}_{\mathrm{T}} \ln \mathrm{A}_{\mathrm{T}}+\mathrm{B}_{\mathrm{T}} \operatorname{Ln} \mathrm{C}_{\mathrm{e}}$

which will give the value of $A_{T}$ associated with the Temkin isotherm equilibrium binding constant $(\mathrm{L} / \mathrm{g})$, and $\mathrm{B}_{\mathrm{T}}$ which depicts the Temkin isotherm constant, respectively. The $\mathrm{B}_{\mathrm{T}}$ value could be derived to calculate the $\mathrm{b}$ constant, related to the heat of adsorption $(\mathrm{kJ} / \mathrm{mol})$, through Eq. (6):

$\mathrm{B}_{\mathrm{T}}=\frac{\mathrm{RT}}{\mathrm{b}}$

The Dubinin-Radushkevich (D-R) isotherm model does not follow the Langmuir model assumption on a homogenous surface or a constant adsorption potential. Rather, the D-R isotherm focuses on describing the physical and chemical features of adsorption of a single solute system. The linearized $\mathrm{D}-\mathrm{R}$ isotherm is expressed as: $\ln \mathrm{q}_{\mathrm{e}}=\ln \mathrm{q}_{\max }-\beta \varepsilon^{2}$

where $\beta$ is the coefficient related to the mean free energy of adsorption [4] per mol of the adsorbate $\left(\mathrm{mol}^{2} / \mathrm{J}^{2}\right)$. The $\mathrm{q}_{\max }$ and $\beta$ were calculated from the slope and intercept of the linear plot of $\ln \mathrm{q}_{\mathrm{e}}$ versus $\varepsilon^{2}$. The $\varepsilon$ is the Polanyi potential expressed as:

$\varepsilon=\mathrm{RT} \ln \left(1+\frac{1}{\mathrm{C}_{\mathrm{e}}}\right)$

in which $\mathrm{R}(\mathrm{J} / \mathrm{mol} \mathrm{K})$ is the gas constant and $\mathrm{T}(\mathrm{K})$ is the absolute temperature. The value of $\beta$ is related to sorption energy $\mathrm{E}(\mathrm{kJ} / \mathrm{mol})$ and is expressed by the relationship:

$$
\mathrm{E}=\frac{1}{(2 \beta)^{0.5}}
$$

The $\mathrm{E}$ value which falls in in the range of $1-8 \mathrm{~kJ} / \mathrm{mol}$ indicates the main mechanism of adsorption is physical adsorption, a value between 8 to $16 \mathrm{~kJ} / \mathrm{mol}$ is related to ion-exchange, whereas chemisorption is predicted for $\mathrm{E}$ value in the range of $20-40 \mathrm{~kJ} / \mathrm{mol}$ [30].
Meanwhile, error analysis was performed using squares of the errors (SSE), residual root mean square error (RMSE), and Chi-square test, $\mathrm{x}^{2}$, to evaluate the fitness of the isotherm data with the regression coefficient, $\mathrm{r}^{2}$, determined from the linearized model.

$\mathrm{SSE}=\sum_{\mathrm{i}=1}^{\mathrm{n}}\left(\mathrm{q}_{\mathrm{e}, \text { meas }}-\mathrm{q}_{\mathrm{e}, \text { calc }}\right)^{2}$

RMSE $=\sqrt{\sum_{i=1}^{n}\left(q_{e, \text { meas }}-q_{e, \text { calc }}\right)^{2}}$

Chi - square, $x^{2}=\frac{\sum_{i=1}^{n}\left(q_{e, \text { meas }}-q_{e, \text { calc }}\right)^{2}}{q_{e, \text { meas }}}$

where $\mathrm{q}_{e, \text { meas, }}$ and $\mathrm{q}_{\mathrm{e}, \text { calc }}$ is the equilibrium adsorption capacity $(\mathrm{mg} / \mathrm{g})$ that is measured experimentally and calculated from the isotherm adsorption model, respectively, while $\mathrm{n}$ is referred to the number of experimental observations.

The adsorption data of both RK and 0.5 M AAK poorly fit the linearized Langmuir isotherm and gives an unusual negative value of $\mathrm{K}_{\mathrm{L}}$ and $\mathrm{q}_{\max }$ (Table 1). This showed the linearized Langmuir isotherm is unsuitable to be used to describe the adsorption process for both adsorbents.

On the other hand, both the empirical data of RK and $0.5 \mathrm{M} \mathrm{AAK}$ is well-fitted with the Freundlich adsorption isotherm model $\left(\mathrm{r}^{2}>0.94\right)$ (Table 1) thus allowing a fair comparison on adsorption isotherm properties between both adsorbents. A good agreement with the Freundlich isotherm model indicated a multilayer and heterogeneous adsorption. The typical value of $1 / \mathrm{n}$ is usually ranged from 0 to 1 , however, the $1 / \mathrm{n}$ values obtained from the Freundlich model were above 1 (Table 1). This suggested that cooperative adsorption may occur raised by attractive adsorbateadsorbate interaction. The binding of an MB molecule to one site on kaolinite may synergically facilitate the adsorption of subsequent molecules towards the active sites. Previous studies on the adsorption of dyes had also reported similar findings [26,31]. Furthermore, these results were in accordance with the S-type adsorption isotherm (according to classification by Giles et al. [32] 
Table1. Parameters of adsorption isotherm model for all adsorbents

\begin{tabular}{lll}
\hline Isotherm model/Adsorbent & \multicolumn{1}{c}{$\mathrm{RK}$} & $0.5 \mathrm{M} \mathrm{AAK}$ \\
\hline Langmuir & & \\
$\mathrm{q}_{\max }(\mathrm{mg} / \mathrm{g})$ & -1.125 & -2.786 \\
$\mathrm{~K}_{\mathrm{L}}(\mathrm{L} / \mathrm{mg})$ & -0.1707 & -1.3282 \\
$\mathrm{r}^{2}$ & 0.7724 & 0.3518 \\
$\mathrm{SSE}$ & 0.0223 & 1.2410 \\
$\mathrm{RMSE}$ & 0.1492 & 1.1140 \\
Chi-square $\left(\mathrm{x}^{2}\right)$ & 0.0299 & 1.2553 \\
\hline Freundlich & & \\
$1 / \mathrm{n}$ & 2.4014 & 1.2814 \\
$\mathrm{~K}_{\mathrm{f}}(\mathrm{L} / \mathrm{g})$ & 0.1289 & 0.5834 \\
$\mathrm{r}^{2}$ & 0.9441 & 0.9452 \\
$\mathrm{SSE}$ & 0.0318 & 0.0236 \\
$\mathrm{RMSE}$ & 0.1783 & 0.1536 \\
Chi-Square $\left(\mathrm{x}^{2}\right)$ & 0.0427 & 0.0300 \\
\hline $\mathrm{D}-\mathrm{R}$ & & \\
$\mathrm{q}_{\max }(\mathrm{mg} / \mathrm{g})$ & 2.077 & 1.906 \\
$\mathrm{E}(\mathrm{kJ} / \mathrm{mol})$ & 0.707 & 1.118 \\
$\mathrm{r}^{2}$ & 0.9221 & 0.9551 \\
$\mathrm{SSE}$ & 0.3341 & 0.3530 \\
$\mathrm{RMSE}$ & 0.5780 & 0.5941 \\
Chi-square $\left(\mathrm{x}^{2}\right)$ & 2.4754 & 2.7423 \\
\hline Temkin & & \\
$\mathrm{A}_{\mathrm{T}}(\mathrm{L} / \mathrm{g})$ & 0.906 & 1.849 \\
$\mathrm{~B}_{\mathrm{T}}$ & 1.3074 & 1.009 \\
$\mathrm{~b}(\mathrm{~kJ} / \mathrm{mol})$ & 1.895 & 2.455 \\
$\mathrm{r}^{2}$ & 0.8782 & 0.9520 \\
$\mathrm{SSE}$ & 0.0683 & 0.0269 \\
$\mathrm{RMSE}$ & 0.2613 & 0.1640 \\
Chi-square $\left(\mathrm{x}^{2}\right)$ & 0.0767 & 0.0292 \\
\hline & &
\end{tabular}

observed from the plot of adsorption data from both adsorbents (Fig. 4(b)). This type of adsorption isotherm is particularly experienced when the adsorbate has large hydrophobic components, like most dyes [31]. At very low concentration, dye-kaolinite interaction was small and in a concave shape, probably due to the competition with solvent (water). But as the MB concentration increased, the amount of adsorption was enhanced (Fig. 4(b)). The empirical data for the Freundlich isotherm model also demonstrated a small SSE, RMSE and Chisquare $\mathrm{x}^{2}$ value. A small error value indicates the close fitness of the measured experimental data with the theoretical value calculated from each model [33].

Meanwhile, the empirical data of RK demonstrated less fitness to D-R and Temkin isotherm, as compared to 0.5 M AAK (Table 1). D-R isotherm is used to differentiate between the physical or chemical adsorption. The theoretical $\mathrm{E}$ value from the D-R model (Table 1) for both RK and 0.5 M AAK implies that the adsorption is governed by physisorption as the $\mathrm{E}<8 \mathrm{~kJ} / \mathrm{mol}$ [30]. The theoretical $\mathrm{q}_{\max }$ value $(1.906 \mathrm{mg} / \mathrm{g})$ obtained from the $\mathrm{D}-\mathrm{R}$ isotherm was in close agreement with the experimental value obtained by the $0.5 \mathrm{M}$ AAK $(1.37 \mathrm{mg} / \mathrm{g})$. Temkin isotherm is less suitable to describe the RK adsorption $\left(\mathrm{r}^{2}<0.9\right)$ but showed good fit with 0.5 M AAK $\left(\mathrm{r}^{2}>0.95\right)$ with small $x^{2}$ value. A positive value of $b$ retrieved from the Temkin isotherm model suggested that the adsorption is of endothermic process. The heat of adsorption is also less than $8 \mathrm{~kJ} / \mathrm{mol}$ indicating a physical adsorption process, which is in good agreement with the findings obtained from the D-R isotherm previously.

\section{Kinetics}

The kinetic studies were performed and fitted through the pseudo first order and second order model. The linear form of the pseudo first order model (known as Lagergren model) [34] is expressed by:

$\log \left(\mathrm{q}_{\mathrm{e}}-\mathrm{q}_{\mathrm{t}}\right)=\log \mathrm{q}_{\mathrm{e}}-\frac{\mathrm{K}_{\mathrm{l}} \mathrm{t}}{2.303}$

where $\mathrm{q}_{\mathrm{t}}$ and $\mathrm{q}_{\mathrm{e}}$ are the amounts of $\mathrm{MB}$ adsorbed in $\mathrm{mg} / \mathrm{g}$ at time $\mathrm{t}(\mathrm{min})$ and at equilibrium, respectively. $K_{1}$ is assigned to the pseudo first order adsorption rate constant $\left(\mathrm{min}^{-1}\right)$ obtained from the slope of the plots of $\log \left(\mathrm{q}_{\mathrm{e}}-\mathrm{q}_{\mathrm{t}}\right)$ versus $\mathrm{t}$.

Meanwhile, the pseudo second order model [35] assumes chemisorption as the rate limiting step and could be expressed by the Eq. (14):

$\frac{\mathrm{t}}{\mathrm{q}_{\mathrm{t}}}=\frac{1}{\mathrm{~h}}+\frac{1}{\mathrm{q}_{\mathrm{e}}} \mathrm{t}$

where $\mathrm{h}$ is the initial sorption rate (mg/g.min). The values of $\mathrm{q}_{\mathrm{e}}$ and $\mathrm{h}$ were calculated from the slope and intercept of the linear plot of $t / q_{t}$ against $t$, respectively. In addition, the pseudo second order constant, $\mathrm{K}_{2}$ (g/mg.min) is derived from the relationship in Eq. (15): $\mathrm{h}=\mathrm{K}_{2} \mathrm{q}_{\mathrm{e}}$ 
The pseudo second order kinetic model demonstrated the best fit $\left(r^{2}>0.98\right.$ and smaller SSE, RMSE and $\mathrm{x}^{2}$ ) to the adsorption data for both RK and 0.5 M AAK compared to pseudo first order model (Table 2). Therefore, chemisorption is deduced to be the rate limiting step for $\mathrm{MB}$ adsorption by both kaolinite adsorbents [28].

\section{Desorption Experiments}

Desorption studies are important in order to investigate the retention stability of adsorbent-adsorbate and validate their reliability for regeneration purpose. Strong adsorbent-pollutant interaction is necessary to ensure no leaching of adsorbed pollutant occurred during the treatment process. On the other hand, if the research emphasizes towards generating a cost-effective treatment, efficient desorption (or recoveries) of a pollutant from spent adsorbent is the first crucial step to allow the adsorbent to be regenerated. Interestingly, although both adsorbents showed almost similar removal percentage of MB during adsorption (95.3 and $96.8 \%$ for RK and $0.5 \mathrm{M}$ AAK, respectively), their desorption profile exhibit a distinctive pattern. The $0.5 \mathrm{M}$ AAK showed less desorption percentage than $\mathrm{RK}$ at $\mathrm{pH} 8$, but the trend was reversed at pH 4 and 6 (Fig. 5). It was proposed that activation may cause protonated surface sites as a consequence of $\mathrm{H}^{+}$ (from $\mathrm{HCl}$ ) interaction with clay's surface during activation [22]. Furthermore acid activation may induce changes in pore structure and size distribution [22]. The protonated surface of $0.5 \mathrm{M} \mathrm{AAK}$ and broad band of pore size hence create less retention capability to hold the adsorbed MB molecules, causing a greater $\mathrm{MB}$ released during desorption studies. Besides, the prevalence of $\mathrm{H}^{+}$ions in the acidic solution (especially at $\mathrm{pH} 4$ ) may be exchangeable with the MB deposited on kaolinite's surface and trigger the desorption of $\mathrm{MB}$ into the solution [36].

Meanwhile, at $\mathrm{pH} 8$, deprotonation by excessive hydroxyl ions $\left(\mathrm{OH}^{-}\right)$on part of $0.5 \mathrm{M}$ AAK surface was predicted. This deprotonation may cause charge delocalization and concurrently strengthen MB-kaolinite retention. Hence less embedded $\mathrm{MB}$ was released towards the aqueous solution during desorption. It was also proposed that the low desorption percentage of dyes in
Table 2. Kinetic analysis on the adsorption of MB by RK and $0.5 \mathrm{M} \mathrm{AAK}$ (performed at initial $[\mathrm{MB}]=50 \mathrm{mg} / \mathrm{L}$, agitation speed $2500 \mathrm{rpm}$, at $0.05 \mathrm{~g} / \mathrm{mL}$ loading, at $25^{\circ} \mathrm{C}$ )

\begin{tabular}{lcc}
\hline Kinetic model/Adsorbent & $\mathrm{RK}$ & $0.5 \mathrm{M} \mathrm{AAK}$ \\
\hline Pseudo first order & & \\
$\mathrm{q}_{\mathrm{e}}(\mathrm{mg} / \mathrm{g})$ & 0.5652 & 0.2412 \\
$\mathrm{k}_{1}\left(\mathrm{~min}^{-1}\right)$ & 0.0404 & 0.0324 \\
$\mathrm{r}^{2}$ & 0.7127 & 0.7180 \\
$\mathrm{SSE}$ & 1.9027 & 1.4078 \\
$\mathrm{RMSE}$ & 1.3794 & 1.1865 \\
Chi-square $\left(\mathrm{x}^{2}\right)$ & 1.9959 & 1.2863 \\
\hline Pseudo second order & & \\
$\mathrm{q}_{\mathrm{e}}(\mathrm{mg} / \mathrm{g})$ & 1.0933 & 1.0054 \\
$\mathrm{k}_{2}\left(\mathrm{~g} \mathrm{mg} \mathrm{mg}^{-1} \mathrm{~min}^{-1}\right)$ & 0.0641 & 0.1939 \\
$\mathrm{~h}\left(\mathrm{~g} \mathrm{mg}{ }^{-1} \mathrm{~min}^{-1}\right)$ & 0.0801 & 0.2120 \\
$\mathrm{r}^{2}$ & 0.9896 & 0.9975 \\
SSE & 0.0167 & 0.0121 \\
$\mathrm{RMSE}$ & 0.1294 & 0.1101 \\
Chi-square $\left(\mathrm{x}^{2}\right)$ & 0.0289 & 0.0162 \\
\hline
\end{tabular}

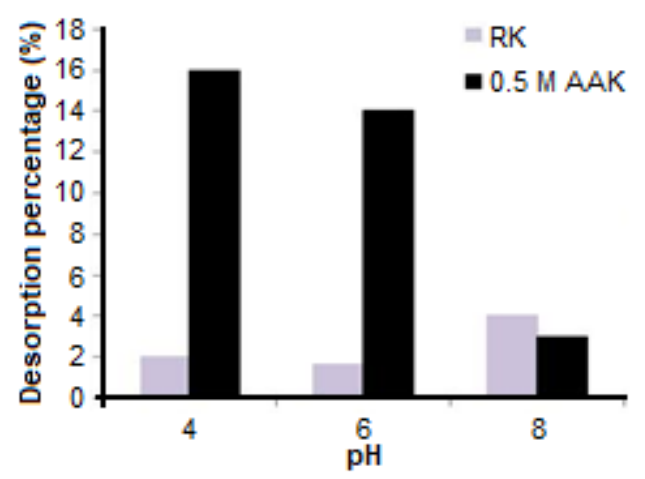

Fig 5. MB desorption efficiency (\%) by spent kaolinites

highly alkaline eluent could probably be due to new complexes that were formed [36]. As the MB desorption percentage in RK was less than $5 \%$, it can be concluded that the kaolinite-MB retention on RK was stronger and irreversible as compared to the $0.5 \mathrm{M}$ AAK. Nevertheless, for the purpose of regeneration and adsorbent recycling, $0.5 \mathrm{M} \mathrm{AAK}$ is a more promising material as the loaded MB is easier to be leached out from the spent clays during desorption process.

\section{- CONCLUSION}

Acid activation provides a simple and inexpensive approach for kaolinite modification. The $0.5 \mathrm{M}$ AAK gave 
higher removal percentage (up to 97\%) but of similar performance against raw kaolinite. The removal of MB by kaolinites in aqueous water is achieved via physisorption while the rate limiting step is governed by the chemisorption. High adsorbent loading, initial concentration, and agitation speed have enhanced the $\mathrm{MB}$ removal percentage. While the $\mathrm{MB}$ removal performance between RK and 0.5 M AAK was analogous, the findings from the desorption experiment showed that the kaolinite-MB retention in the spent RK was irreversible and more stable against $\mathrm{pH}$ influence. Hence, the forthcoming regeneration process of spent acid-activated kaolinite for re-use in water treatment is expected to be more feasible as compared to raw clays. Overall, kaolinite has shown a promising application in treating dyes from contaminated water.

\section{- ACKNOWLEDGMENTS}

The authors would like to thank Universiti Teknologi MARA, Negeri Sembilan branch for technical facilities and financial support through internal funding, also the anonymous reviewers for their feedback to improve the manuscript.

\section{- REFERENCES}

[1] Bafana, A., Devi, S.S., and Chakrabarti, T., 2011, Azo dyes: Past, present and the future, Environ. Rev., 19, 350-371.

[2] Kallel, F., Chaari, F., Bouaziz, F., Bettaieb, F., Ghorbel, R., and Chaabouni, S.E., 2016, Sorption and desorption characteristics for the removal of a toxic dye, methylene blue from aqueous solution by a low cost agricultural by-product, J. Mol. Liq., 219, 279-288.

[3] Rafatullah, M., Sulaiman, O., Hashim, R., and Ahmad, A., 2010, Adsorption of methylene blue on low-cost adsorbents: A review, J. Hazard. Mater., 177 (1-3), 70-80.

[4] Rida, K., Bouraoui, S., and Hadnine, S., 2013, Adsorption of methylene blue from aqueous solution by kaolin and zeolite, Appl. Clay Sci., 83-84, 99-105.

[5] Bergaya, F., and Lagaly, G., 2006, "Chapter 1 General introduction: Clays, clay minerals, and clay science" in Handbook of Clay Science, $1^{\text {st }}$ Ed., Eds. Bergaya, F.,
Theng, B.K.G., and Lagaly, G., Elsevier Science, Netherlands, 1-18.

[6] Zhou, C.H., and Keeling, J., 2013, Fundamental and applied research on clay minerals: From climate and environment to nanotechnology, Appl. Clay Sci., 74, 3-9.

[7] Madejova, J., and Komadel, P., 2001, Baseline studies of the clay minerals society source clays: Infrared methods, Clays Clay Miner., 49 (5), 410-432.

[8] Rusmin, R., Sarkar, B., Biswas, B., Churchman, J., Liu, Y., and Naidu, R., 2016, Structural, electrokinetic and surface properties of activated palygorskite for environmental application, Appl. Clay Sci., 134, 95-102.

[9] Shi, L., 2017, "The mineral industry of Malaysia" in Minerals Yearbook 2014: Metals and Minerals, Vol. I, U.S. Geological Survey, Reston, VA, 16.1-16.7.

[10] Gao, W., Zhao, S., Wu, H., Deligeer, W., and Asuha, S., 2016, Direct acid activation of kaolinite and its effects on the adsorption of methylene blue, Appl. Clay Sci., 126, 98-106.

[11] Komadel, P., 2016, Acid activated clays: Materials in continuous demand, Appl. Clay Sci., 131, 84-99.

[12] Hai, Y., Li, X., Wu, H., Zhao, S., Deligeer, W., and Asuha, S., 2015, Modification of acid-activated kaolinite with $\mathrm{TiO}_{2}$ and its use for the removal of azo dyes, Appl. Clay Sci., 114, 558-567.

[13] Wu, P., and Ming, C., 2006, The relationship between acidic activation and microstructural changes in montmorillonite from Heping, China, Spectrochim. Acta, Part A, 63 (1), 85-90.

[14] Sarma, G.K., Gupta, S.S., and Bhattacharyya, K.G., 2019, Removal of hazardous basic dyes from aqueous solution by adsorption onto kaolinite and acid-treated kaolinite: Kinetics, isotherm, and mechanistic study, SN Appl. Sci., 1, 211.

[15] El Mouzdahir, Y., Elmchaouri, A., Mahboub, R., Gil, A., and Korili, S.A., 2010, Equilibrium modeling for the adsorption of methylene blue from aqueous solutions on activated clay minerals, Desalination, 250 (1), 335-338.

[16] Vanaamudan, A., Pathan, N., and Pamidimukkala, P., 2014, Adsorption of Reactive Blue 21 from 
aqueous solutions onto clay, activated clay, and modified clay, Desalin. Water Treat., 52 (7-9), 15891599.

[17] Hu, P., and Yang, H., 2013, Insight into the physicochemical aspects of kaolins with different morphologies, Appl. Clay Sci., 74, 58-65.

[18] Frost, R.L., 1997, The structure of the kaolinite minerals FT-Raman study, Clay Miner., 32 (1), 65-77.

[19] Saikia, B.J., and Parthasarathy, G., 2010, Fourier transform infrared spectroscopic characterization of kaolinite from Assam and Meghalaya, Northeastern India, J. Mod. Phys., 1, 206-210.

[20] Panda, A.K., Mishra, B.G., Mishra, D.K., and Singh, R.K., 2010, Effect of sulphuric acid treatment on the physico-chemical characteristics of kaolin clay, Colloids Surf., A, 363, 98-104.

[21] Ullah, Z., Hussain, S., Gul, S., Khan, S., and Bangash, F.K., 2016, Use of HCl-modified bentonite clay for the adsorption of Acid Blue 129 from aqueous solutions, Desalin. Water Treat., 57 (19), 8894-8903.

[22] Bhattacharyya, K.G., and Gupta, S.S., 2011, Removal of $\mathrm{Cu}$ (II) by natural and acid-activated clays: An insight of adsorption isotherm, kinetic and thermodynamics, Desalination, 272 (1-3), 66-75.

[23] Chicinaş, R.P., Bedelean, H., Stefan, R., and Măicăneanu, A., 2018, Ability of a montmorillonitic clay to interact with cationic and anionic dyes in aqueous solutions, J. Mol. Struct., 1154, 187-195.

[24] Mills, A., Hazafy, D., Parkinson, J., Tuttle, T., and Hutchings, M.G., 2011, Effect of alkali on methylene blue (C.I. Basic Blue 9) and other thiazine dyes, Dyes Pigm., 88 (2), 149-155.

[25] Tehrani-Bagha, A.R., Nikkar, H., Mahmoodi, N.M., Markazi, M., and Menger, F.M., 2011, The sorption of cationic dyes onto kaolin: Kinetic, isotherm, and thermodynamic studies, Desalination, 266 (1-3), 274-280.

[26] Berrios, M., Martín, M.Á., and Martín, A., 2012, Treatment of pollutants in wastewater: Adsorption of methylene blue onto olive-based activated carbon, $J$. Ind. Eng. Chem., 18 (2), 780-784.
[27] Vimonses, V., Lei, S., Jin, B., Chow, C.W.K., and Saint, C., 2009, Kinetic study and equilibrium isotherm analysis of Congo Red adsorption by clay materials, Chem. Eng. J., 148 (2-3), 354-364.

[28] Auta, M., and Hameed, B.H., 2013, Acid modified local clay beads as an effective low-cost adsorbent for dynamic adsorption of methylene blue, J. Ind. Eng. Chem., 19 (4), 1153-1161.

[29] Temkin, M.J., and Pyzhev, V., 1940, Recent modification to Langmuir isotherms, Acta Physicochim. URSS, 12, 217-222.

[30] Desta, M.B., 2013, Batch sorption experiments: Langmuir and Freundlich isotherm studies for the adsorption of textile metal ions onto Teff Straw (Eragrostis tef) agricultural waste, J. Thermodyn., 2013, 375830.

[31] Gómez, V., Larrechi, M.S., and Callao, M.P., 2007, Kinetic and adsorption study of acid dye removal using activated carbon, Chemosphere, 69 (7), 11511158 .

[32] Giles, C.H., MacEwan, T.H., Nakhwa, S.N., and Smith, D., 1960, Studies in adsorption. Part XI. A system of classification of solution adsorption isotherms, and its use in the diagnosis of adsorption mechanisms and in the measurement of specific surface areas of solids, J. Chem. Soc., 14, 3973-3993.

[33] Zamri, T.K.A.T.M., Munaim, M.S.A., and Wahid, Z.A., 2017, Regression analysis for the adsorption isotherms of natural dyes onto bamboo yarn, Int. Res. J. Eng. Technol., 4 (6), 1699-1703.

[34] Yuh-Shan, H., 2004, Citation review of Lagergren kinetic rate equation on adsorption reactions, Scientometrics, 59, 171-177.

[35] Ho, Y.S., 2006, Review of second-order models for adsorption systems, J. Hazard. Mater., 136 (3), 681689.

[36] Daneshvar, E., Vazirzadeh, A., Niazi, A., Kousha, M., Naushad, M., and Bhatnagar, A., 2017, Desorption of Methylene blue dye from brown macroalga: Effects of operating parameters, isotherm study, and kinetic modeling, J. Cleaner Prod., 152, 443-453. 